\title{
The 3D Elevation Program and Energy for the Nation
}

\section{Energy Infrastructure and High- Quality Three-Dimensional Elevation Data}

High-resolution light detection and ranging (lidar) data are used in energy infrastructure siting, design, permitting, construction, and monitoring to promote public safety through reduction of risks. For example, lidar data are used to identify safe locations for energy infrastructure by analyzing terrain parameters and identifying and evaluating geologic hazards (for example, landslide and fault locations) and their potential public safety effects on the location or design of infrastructure. Increasingly, engineering companies and regulatory agencies are using lidar and other remote sensing techniques as an efficient method to collect accurate, comprehensive data while reducing risks to field personnel.

The U.S. Geological Survey (USGS) 3D Elevation Program (3DEP) is collecting lidar data nationwide (interferometric synthetic aperture radar [IfSAR] data in Alaska) to support a wide range of applications, including projects related to energy infrastructure construction and safety (fig. 1). Renewable energy resources, resource mining, and oil and gas resources were identified by the National Enhanced Elevation Assessment (Dewberry, 2012) as business uses requiring three-dimensional (3D) elevation data (table 1).

Elevation data are critical in assessing potential sites for energy infrastructure, such as pipelines, refineries, and other facilities, to mitigate risks from natural hazards. For example, the Federal Energy Regulatory Commission (FERC), an independent agency that regulates the interstate transmission of electricity, natural gas, and oil, uses enhanced elevation data to conduct National Environmental Policy Act (NEPA) compliance assessments. The acquisition of high-resolution lidar data by the USGS 3DEP initiative helps the FERC and NEPA permit applicants by providing accurate and consistent data for hazards analysis. The use of these data accelerates the application and review process and avoids the much higher costs of field crews acquiring elevation data along proposed energy facility locations and pipeline corridors.

Table 1. Conservative annual national benefits of $3 \mathrm{D}$ Elevation Program data related to the energy sector (Dewberry, 2012).

\begin{tabular}{lc}
\hline \multicolumn{1}{c}{ Business use } & $\begin{array}{c}\text { Conservative } \\
\text { annual benefit } \\
\text { (million dollars) }\end{array}$ \\
\hline $\begin{array}{c}\text { Infrastructure and con- } \\
\text { struction management }\end{array}$ & 18.1 \\
$\begin{array}{l}\text { Renewable energy } \\
\text { resources }\end{array}$ & 2.6 \\
$\begin{array}{l}\text { Oil and gas resources } \\
\text { Resource mining }\end{array}$ & 1.6 \\
\hline Water supply and quality & 0.8 \\
Total & 0.8 \\
\hline
\end{tabular}

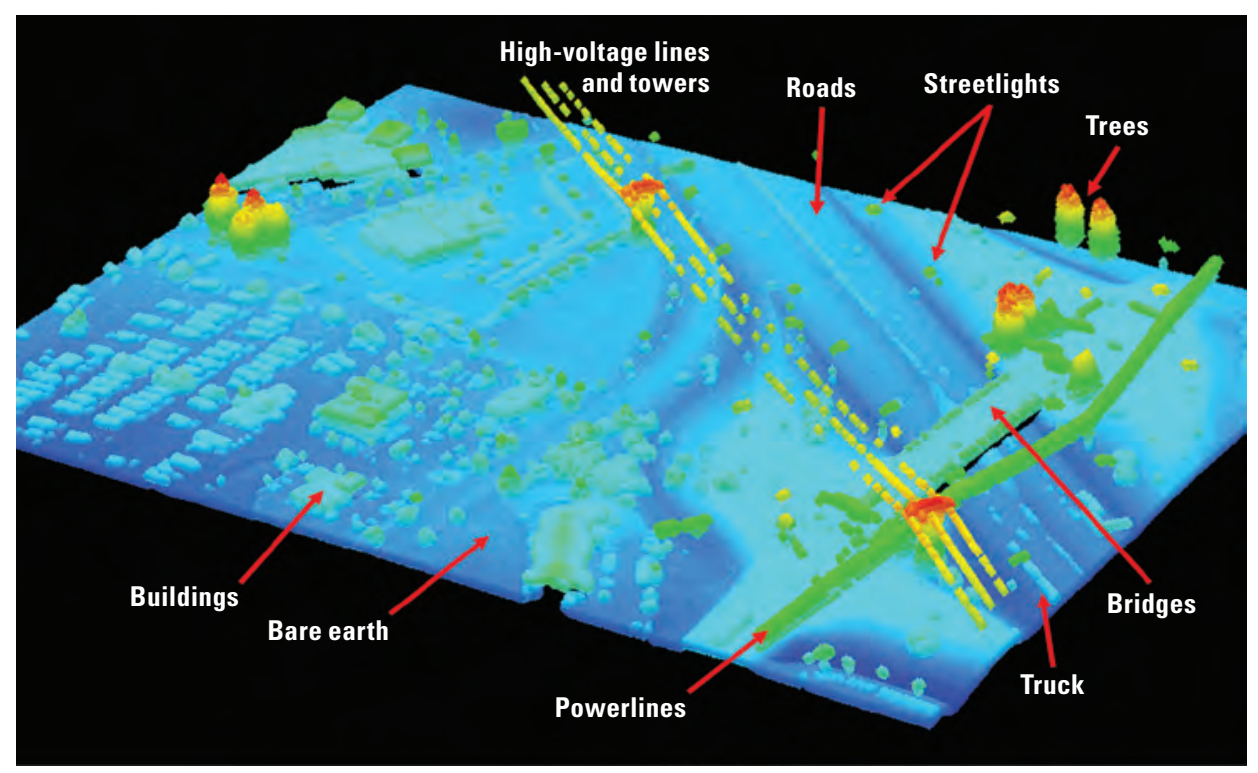

Figure 1. A light detection and ranging (lidar) point cloud image that captures power transmission lines and other infrastructure. Image courtesy of Jason Stoker, U.S. Geological Survey.

\section{D Elevation Program (3DEP)}

The 3D Elevation Program (3DEP) is managed by the U.S. Geological Survey (USGS) on behalf of Federal, State, local, and other partners and users of elevation data. The goal of 3DEP is to complete the acquisition of light detection and ranging (lidar) data (interferometric synthetic aperture radar [IfSAR] data in Alaska) in 8 years to provide the first-ever national baseline of consistent, high-resolution elevation data.

\section{Benefits}

- Economies of scale by acquiring data for larger areas.

- Predictable and flexible Federal investments that reduce costs and allow better planning.

- Consistent national coverage that provides data ready for applications that span project, jurisdictional, and watershed boundaries.

- Simplified data acquisition that provides contracts, project management, quality assurance, and published dataacquisition specifications.

- New benefits of $\$ 690$ million per year conservatively, with the potential to generate $\$ 13$ billion per year in additional benefits through applications that span the economy (Dewberry, 2012).

\section{High-Quality Data and Products}

3DEP lidar provides coverage with a minimum of two points per square meter and a vertical error not to exceed 10 centimeters, measured as root mean square error in the elevation $(z)$ dimension $\left(\mathrm{RMSE}_{z}\right)$. Lidar data products include all data points collected (point cloud) and a bare-earth digital elevation model with a 1-meter resolution. 


\section{Uses of Three-Dimensional Elevation Data in the Energy Sector}

Uses of 3D elevation data in the energy sector include the following:

Spill impact analysis - Lidar-based digital elevation models are used to predict the extent of damage caused by pipeline leaks, which is largely influenced by the surrounding terrain. Spill impact analyses can be completed for pipeline leak scenarios to predict the risks to sensitive ecosystems or populated areas.

Hydroelectric dam risk assessment-High-resolution elevation data are used in flood risk mapping for hydroelectric dam failures and their potential effects on public safety and natural and built environments. Lidar and IfSAR data are used to analyze dam breaks and to understand the effects of floods, landslides, and earthquakes on dams.

Nuclear reactor siting-Assessing seismic hazards is a critical component in siting nuclear power plants. Lidar data are used to refine the identification of surface-faulting geologic/tectonic structures (fig. 2), potential liquefaction sites, potential landslide areas, karst topography, surfacewater drainage, coastal flooding extents, and other flood-prone areas that are considered in the assessment of potential sites. The use of high-quality elevation data to evaluate hazards provides information for public health and safety decisions and allows the Nuclear Regulatory Commission to complete efficient and effective technical reviews.

Solar energy potential-3D elevation data are used by the solar energy industry to calculate the amount of irradiance (sunlight) and shading cast on a rooftop by nearby buildings, trees, and chimneys and to evaluate roof slope and aspect (fig. 3). This information can be collected remotely by using lidar, avoiding the need for expensive and potentially dangerous site visits to measure roof irradiance.

Power generation and transmission facility design - To effectively design, site, and construct energy infrastructure such as power generating facilities and transmission lines, utility companies require accurate topographic data. For example, the Tennessee Valley Authority (TVA) requires high-quality lidar data to accurately model flood risks for power generating plants and major substations. The TVA also uses lidar data for the inspection of transmission line right-ofways to maintain required clearance from trees and encroachments.

Figure 2. A 1-meter digital elevation model, created from light detection and ranging (lidar) data, that depicts part of the Meers fault in southwestern Oklahoma. Image was derived from the Federal Emergency Management Agency Cache Creek Basin lidar project.
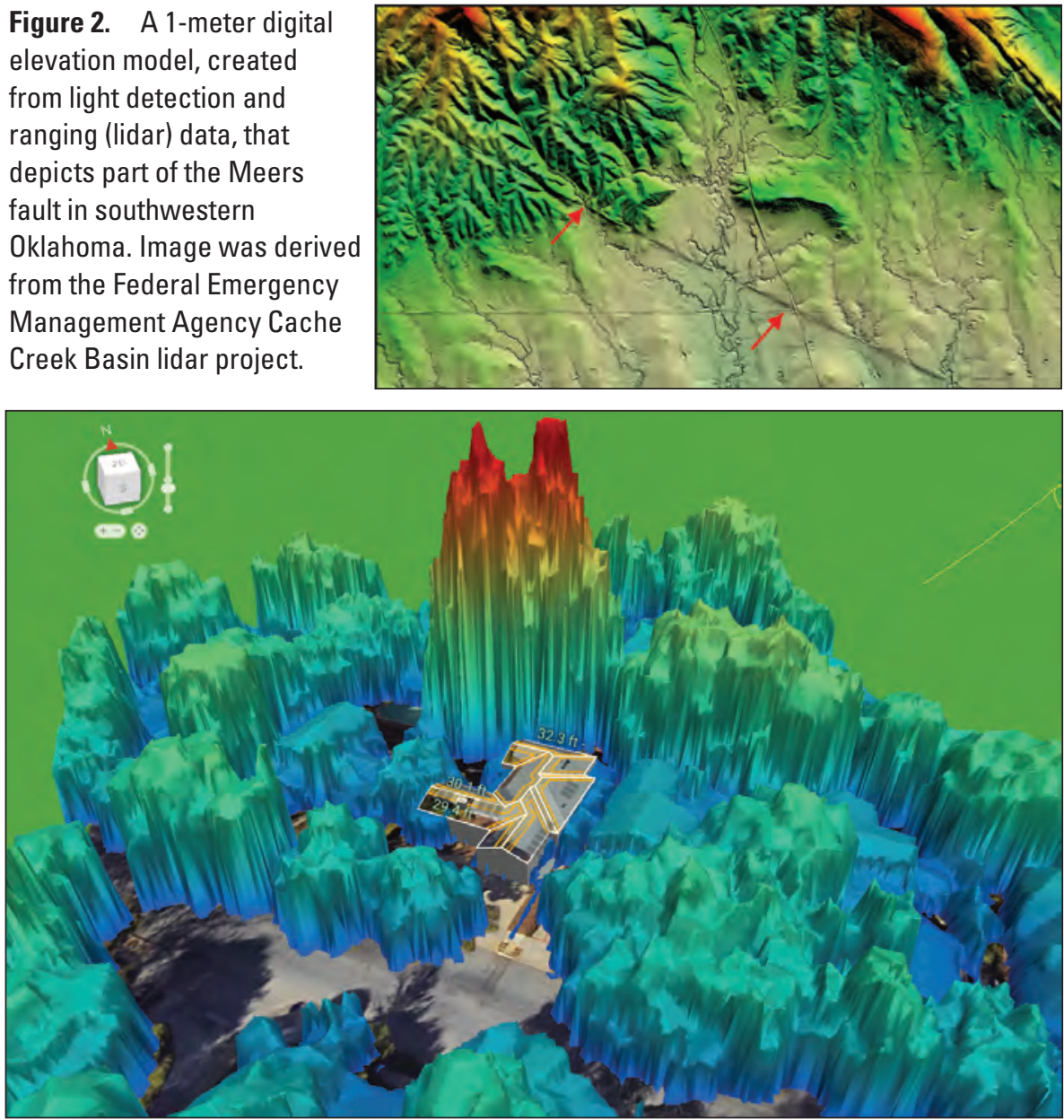

Figure 3. A light detection and ranging (lidar)-based three-dimensional model of a building rooftop and surrounding trees and obstructions used to quantify the solar energy potential of a site. Image courtesy of Aurora Solar Inc. (http://www.aurorasolar.com/), used with permission.

\section{D Elevation Program- Continued}

The USGS integrates the elevation data into The National Map. Data are available free of charge and without use restrictions. To download 3DEP products, visit https://viewer.nationalmap.gov/basic/.

\section{Ways to Participate}

3DEP participation is open to Federal, State, Tribal, U.S. territorial, and local government partners, as well as private sector partners, and offers the option to acquire higher quality data. Partners may contribute funds toward projects managed by the USGS, or they may receive cooperative funds to manage their own projects. An annual Broad Agency Announcement is the mechanism used to establish partner agreements. Organizations and the private sector may contribute existing data that meet 3DEP requirements. For more information, see the 3DEP website at https://usgs. gov/3DEP/collaborate.

\section{Reference Cited}

Dewberry, 2012, Final report of the National Enhanced Elevation Assessment (revised March 29, 2012): Fairfax, Va., Dewberry, 84 p. plus appendixes, accessed June 12, 2017, at http:// www.dewberry.com/Consultants/GeospatialMapping/FinalReport-NationalEnhancedElevationAssessment.

Any use of trade, product, or firm names is for descriptive purposes only and does not imply endorsement by the U.S. Government.

\section{-By Cindy A. Thatcher, Vicki Lukas, and Jason M. Stoker}

\section{Learn More about 3DEP}

Please send questions to: Director, National Geospatial Program U.S. Geological Survey 12201 Sunrise Valley Drive, MS 511 Reston, VA 20192

Email: 3DEP@usgs.gov

ISSN 2327-6932 (online) https://doi.org/10.3133/fs20193051 